The Journal of Rheumatology 2021;48:12

doi:10.3899/jrheum.210750

First Release September 12021

\section{Dr. Mease et al reply}

\section{To the Editor:}

We thank Dr. Maguire et $\mathrm{al}^{1}$ for their interest in and appreciation of our study from the Corrona Psoriatic Arthritis/ Spondyloarthritis Registry comparing patient characteristics and disease burden between men and women with axial spondyloarthritis (axSpA). ${ }^{2}$ Dr. Maguire and colleagues raised a number of interesting questions around the causal relationship between the higher prevalence of depression and decreased work productivity we observed in women in our study. While we were unable to directly address these questions in the Registry, we agree and appreciate that these are important research priorities for future investigations.

As we noted in our study, limited information exists on the overall disease burden of axSpA in women in the US, as women are generally underrepresented in clinical studies. Further, much of our understanding of axSpA disease burden in women is based on data from patients with ankylosing spondylitis. Our historical understanding of sex differences in axSpA is limited. ${ }^{3}$

While the higher prevalence of depression in women with axSpA may drive worse levels of function and decreased work productivity, the causal link remains unclear. Globally, more women than men perform unpaid labor, ${ }^{4}$ which is associated with poorer mental health. ${ }^{5}$ Constraints on women's professional advancement, such as the gender wage gap, may also contribute to gendered mental health disparities. ${ }^{6}$ Alternatively, as Dr. Maguire and colleagues noted, ${ }^{1}$ worse limitation in functional ability in women with axSpA may contribute to work instability and subsequent depression. Whether women with axSpA are under greater pressure to remain in the workforce remains unclear; however, a gender gap for disability benefits is well established. ${ }^{7}$ Women are substantially more likely to be rejected for disability insurance than men, controlling for health condition, occupation, and multiple demographic characteristics. ${ }^{8}$

As one of the first studies to evaluate differences in clinical and patient-reported disease burden between men and women with axSpA in the US, we hope our findings will spur additional research to further evaluate and understand these differences. We agree with Dr. Maguire and colleagues that future studies examining workforce participation and the effect of mental health in axSpA, especially in women, are paramount. One step in this direction will be gaining a deeper understanding of the influence of central sensitization, which is a broader concept than fibromyalgia and can be more prevalent in women than men. ${ }^{9}$ In our Registry, we have begun to assess this using the Widespread Pain Index/Symptom Severity Scale in order to determine the role of central sensitization more quantitatively on disease burden, response to treatment, comorbidities such as depression, and work productivity.
Philip J. Mease ${ }^{1}$ (D), MD

Robert R. McLean ${ }^{2}$, DSc, MPH

Blessing Dube ${ }^{2}, \mathrm{MPH}$

Mei Liu ${ }^{2}$ PhD

Sabrina Rebello², MPH

Meghan Glynn², MS, CPH

Esther $\mathrm{Yi}^{3}$, PharmD

Yujin Park ${ }^{3}$, PharmD

Alexis Ogdie ${ }^{4}$, MD, MCSE

${ }^{1}$ Swedish Medical Center/Providence St. Joseph Health and

University of Washington, Seattle, Washington;

${ }^{2}$ CorEvitas, LLC, Waltham, Massachusetts;

${ }^{3}$ Novartis Pharmaceuticals Corporation, East Hanover,

New Jersey;

${ }^{4}$ Division of Rheumatology, Perelman School of Medicine, University of Pennsylvania, Philadelphia, Pennsylvania, USA.

This study was sponsored by CorEvitas (formerly Corrona), LLC. CorEvitas, LLC, has been supported through contracted subscriptions in the last 2 years by AbbVie, Amgen, Boehringer Ingelheim, BMS, Celgene, Crescendo, Eli Lilly and Company, Genentech, Gilead, GSK, Janssen, Merck, Momenta Pharmaceuticals, Novartis, Ortho Dermatologics, Pfizer Inc., Regeneron, Roche, Sun, and UCB. The design and conduct of the study were a collaborative effort between CorEvitas, LLC, and Novartis, and financial support for the study was provided by Novartis. Novartis participated in the interpretation of data and review and approval of the manuscript.

PJM has received research grants from AbbVie, Amgen, BMS, Galapagos, Gilead, Janssen, Lilly, Novartis, Pfizer, Sun, and UCB; and consulting and/or speakers bureau fees from AbbVie, Amgen, Boehringer Ingelheim, BMS, Galapagos, Genentech, Gilead, GSK, Janssen, Lilly, Novartis, Pfizer, Sun, and UCB. RRM and BD are employees of CorEvitas, LLC. ML, SR, and MG were employees of Corrona, LLC, at the time of this analysis. EY and YP are employees of Novartis Pharmaceuticals Corporation. AO has received consulting fees from Amgen, AbbVie, BMS, Celgene, Corrona, Janssen, Lilly, Novartis, and Pfizer; and grant support from the National Institutes of Health/National Institute of Arthritis and Musculoskeletal and Skin Diseases, National Psoriasis Foundation, Rheumatology Research Foundation, Pfizer (University of Pennsylvania), Amgen (FORWARD Databank), and Novartis (FORWARD Databank).

Address correspondence to Dr. P.J. Mease, Seattle Rheumatology Associates, 601 Broadway, Suite 600, Seattle, WA 98122, USA.

Email:pmease@philipmease.com.

\section{REFERENCES}

1. Maguire S, Fitzgerald G, O'Shea F. Employment and functional ability in men and women with axial spondyloarthritis as described in the US-based Corrona Psoriatic Arthritis/Spondyloarthritis Registry. J Rheumatol 2021;48:1890-1.

2. Mease PJ, McLean RR, Dube B, Liu M, Rebello S, Glynn M, et al. Comparison of men and women with axial spondyloarthritis in the US-based Corrona Psoriatic Arthritis/Spondyloarthritis Registry. J Rheumatol 2021;48:1528-36.

3. Rusman T, van Vollenhoven RF, van der Horst-Bruinsma IE. Gender differences in axial spondyloarthritis: women are not so lucky. Curr Rheumatol Rep 2018; 20:35.

4. The World Bank. Gender differences in employment and why they matter. In: World development report 2012: gender equality and development. [Internet. Accessed July 14, 2021.] Available from: https://openknowledge.worldbank.org/ handle/10986/4391 
5. Ciciolla L, Luthar SS. Invisible household labor and ramifications for adjustment: mothers as captains of households. Sex Roles 2019;81:467-86.

6. Platt J, Prins S, Bates L, Keyes K. Unequal depression for equal work? How the wage gap explains gendered disparities in mood disorders. Soc Sci Med 2016;149:1-8.

7. Ruffing K. Women and disability insurance: five facts you should know. Center on Budget and Policy Priorities, 2018. [Internet. Accessed July 14, 2021.] Available from: https://www.cbpp.org/ research/social-security/women-and-disability-insurance-five-factsyou-should-know

8. Low H, Pistaferri L. Disability insurance: error rates and gender differences. National Bureau of Economic Research, 2019. [Internet. Accessed July 14, 2021.] Available from: https://www.nber.org/ papers/w26513

9. Mease PJ. Fibromyalgia, a missed comorbidity in spondyloarthritis: prevalence and impact on assessment and treatment. Curr Opin Rheumatol 2017;29:304-10. 